\title{
MCCC2 promotes HCC development by supporting leucine oncogenic function
}

Yu-Yan Chen ${ }^{1,2+}{ }^{\infty}$, Xue-Ning Zhang ${ }^{3 \dagger}{ }^{+}$Chen-Zhou Xu ${ }^{4 \dagger}$, Dan-Hua Zhou ${ }^{3}$, Jing Chen ${ }^{2,3}$, Zhao-Xiu Liu ${ }^{3}$, Ying sun ${ }^{5}$, Wei Huang ${ }^{3^{*}}$ and Li-Shuai Qu ${ }^{3^{*}}$

\begin{abstract}
Background: The role of methylcrotonoyl-CoA carboxylase 2 (MCCC2) in the development of tumors is well-established, and the involvement of leucine in the liver is well-known. However, the role of MCCC2 and the correlation between MCCC2 and leucine in the progression of hepatocellular carcinoma (HCC) have not yet been reported.

Methods: In this study, the Gepia database was used to evaluate the prognostic value of MCCC2 in HCC. The expression and localization of MCCC2 in HCC cells were determined by western blot and immunofluorescence assays. Flow cytometry and CCK-8 and transwell assays were carried out to explore the effect of MCCC2 on cell proliferation, migration, and invasion. In addition, mass spectrometry analysis was used to predict the potential cell function of MCCC2 in HCC.

Results: We found that the expression of MCCC2 increased in HCC tissues and that high expression of MCCC2 could predict poor outcomes in HCC patients. Knockdown expression of MCCC2 in HCC cells could reduce cell proliferation, migration, and invasion ability in vitro and could inhibit HCC cell proliferation in vivo. Interestingly, we found that HCC cells transfected with MCCC2-sgRNA failed to respond to leucine deprivation. Meanwhile, leucine deprivation inhibited cell proliferation, migration, and invasion in HCC cells where MCCC2 was present rather than in cells where MCCC2 was absent. In addition, knockdown of MCCC2 significantly reduced the glycolysis markers, glucose consumption, lactate secretion, and acetyl-CoA level, which is a product of leucine metabolism. Furthermore, we found that MCCC2 promotes the activation of ERK. Profiling the MCCC2 binding proteins revealed that MCCC2-associated proteins are enriched in biological processes, such as protein metabolism, energy pathway, and metabolism in HCC cells.
\end{abstract}

Conclusions: Our findings revealed that MCCC2 plays a critical role in the development of HCC, and the leucine metabolism pathway might be a novel target in HCC treatment.

Keywords: Hepatocellular carcinoma, MCCC2, leucine, ERK, metabolism

\section{Introduction}

Tumors are one of the major causes of death worldwide and have become an important factor hindering the improvement of life expectancy. The incidence and mortality of liver cancer worldwide ranked seventh and

\footnotetext{
*Correspondence: huangweint@ntu.edu.cn; qulishuai1121@163.com

${ }^{\dagger}$ Yu-Yan Chen, Xue-Ning Zhang and Chen-Zhou Xu contributed equally

to this work.

${ }^{3}$ Department of Gastroenterology, Affiliated Hospital of Nantong

University, Nantong, China

Full list of author information is available at the end of the article
}

second for all cancers, respectively, in 2018, accounting for $4.7 \%$ and $8.2 \%$ of all tumors, respectively. Hepatocellular carcinoma (HCC) is the most prevalent type of liver cancer, accounting for $90 \%$ of all liver cancer cases [1], and has a poor prognosis and a high recurrence rate. However, the molecular mechanisms underlying the development of HCC remain largely unclear [2]. Therefore, there is an urgent need to decipher the underlying mechanisms of HCC, which may provide a novel diagnostic and therapeutic strategy for HCC patients.

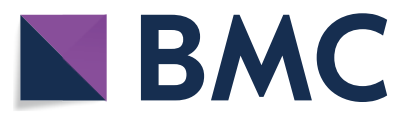

(c) The Author(s) 2021. This article is licensed under a Creative Commons Attribution 4.0 International License, which permits use, sharing, adaptation, distribution and reproduction in any medium or format, as long as you give appropriate credit to the original author(s) and the source, provide a link to the Creative Commons licence, and indicate if changes were made. The images or other third party material in this article are included in the article's Creative Commons licence, unless indicated otherwise in a credit line to the material. If material is not included in the article's Creative Commons licence and your intended use is not permitted by statutory regulation or exceeds the permitted use, you will need to obtain permission directly from the copyright holder. To view a copy of this licence, visit http://creativeco mmons.org/licenses/by/4.0/. The Creative Commons Public Domain Dedication waiver (http://creativecommons.org/publicdomain/ zero/1.0/) applies to the data made available in this article, unless otherwise stated in a credit line to the data. 
A major abnormality of cancer cells is a change in their metabolism [3]. Cancer cells can change their metabolism and obtain the necessary nutrients from an undernourished environment, gain energy, and build new biomass $[4,5]$. Abnormal metabolism of cancer is mainly characterized by upregulation of glucose and amino acid uptake, changes in metabolite-driven gene regulation, interaction with the microenvironment, etc. [6]. LLGL2 can promote the proliferation of tumor cells by accelerating leucine uptake in $\mathrm{ER}^{+}$breast cancer [7]. As one of the branched chain amino acids, leucine can avoid first-pass liver catabolism in the human body to transport nitrogen throughout the body for the synthesis of non-essential amino acids, such as the neurotransmitter glutamate [8]. In some malignant tumors, the growth of tumor cells is also closely related to the catabolism of glutamine $[9,10]$. In addition, there is direct evidence that the inhibition of BCAT1 in glioma cell lines blocks glutamate excretion, leading to reduced proliferation and invasiveness in vitro [11]. These data indicate that different cancers might require particular amino acids for survival because of their distinct oncogenic transformation. However, the role of leucine in $\mathrm{HCC}$ is currently unknown.

3-methylcrotonyl-CoA carboxylase (MCC), a member of the biotin-dependent carboxylase superfamily [12], has a high degree of conservation of PCC. The entire enzymatic structure is a heterododecyl, consisting of six alpha and six beta subunits [13]. MCCase was first discovered in bacteria and mammals 48 years ago [14], and it can decompose leucine into acetoacetate and acetylCoA [15, 16]. By interacting with SIRT4 [17], the activity of MCC increases, thereby promoting the catabolism of leucine [18]. As a subunit of MCC, methylcrotonoyl-CoA carboxylase 2 (MCCC2) is highly expressed in breast and prostate cancers and can promote the proliferation and metastasis of tumor cells [19-21]. For example, the high expression of $\mathrm{MCCC} 2$ predicts a poor prognosis and can promote cell proliferation in colorectal and breast cancer $[19,22]$. The oncogenic role of MCCC2 is partially involved in the GLUD1-P38 MAPK signaling pathway [23]. However, it is currently unclear whether MCCC2 also plays an important role in the progression of $\mathrm{HCC}$ and the effect of MCCC2 on leucine metabolism has yet not been deciphered.

In this study, we found that MCCC2 participates in the utilization of leucine by HCC cells, thereby promoting the proliferation, migration, and invasion of HCC cells.

\section{Materials and methods \\ Cell culture and cell lines}

Human HCC lines (SMCC-7721, SK-HEP1, HepG2, and Huh7) and the normal liver cell line LO2 were obtained from the Shanghai Institute of Cell Biology, Academic
Sinica. The cells were cultured in RPMI 1640 and Dulbecco's modified Eagle's medium (DMEM) (Hyclone, USA; Caisson, USA, Lot:04191017), respectively, supplemented with $10 \%$ (vol/vol) fetal bovine serum (Gibco, USA) $10000 \mathrm{U} / \mathrm{mL}$ penicillin, and $10000 \mu \mathrm{g} / \mathrm{mL}$ streptomycin (Gibco, USA) in $5 \% \mathrm{CO}_{2}$ at $37^{\circ} \mathrm{C}$.

\section{sgRNA construction and stable cell line establishment}

The sgRNAs targeting MCCC2 were a gift from Dr. Li at the Houston Methodist hospital [24]. To establish stable cell lines, SMMC-7721 cells were transfected with the plasmids then screened with $1 \mu \mathrm{g} / \mathrm{mL}$ of puromycin (ApexBio, Houston, TX, USA), and stable expression cell lines were obtained. The protocols were carried out as described previously [25]. The cloned sgRNA sequences were as follows:

SgMCCC2-1: GTGCCCGCGCCTCTCCCGCC; SgMCCC2-2: GCGCGCCTATCACGGGGACT; SgMCCC2-3: GGCCTCGCTGGGCACCCAGC.

\section{Western blot}

Cells were lysed in RIPA lysis buffer $(50 \mathrm{mmol} / \mathrm{L}$ Tris $\mathrm{pH}$ 7.4, $120 \mathrm{mmol} / \mathrm{L} \mathrm{NaCl}, 1 \%$ Triton X-100, 1\% sodium deoxycholate, $0.1 \%$ SDS, Beyotime, Shanghai, China) supplemented with protease inhibitors (Complete Mini, Roche, Basel, Switzerland) and phosphatase inhibitors (PhosSTOP, Roche).

Primary antibodies: MCCC2 (12117-1-AP; Proteintech, Rosemont, IL, USA), PCNA (sc-56, Santa Cruz), c-Myc (\#D84C12; CST, USA), E-cadherin (\#14,472; CST), $\mathrm{N}$-cadherin (\#13,116; CST), MMP9 (\#13,667; CST), phospho-p44/42 MAPK (Erk1/2) (\#4370; CST), p44/42 MAPK (Erk1/2) (\#9102; CST), phospho-Mek1 (Thr286) (\#9127; CST), Flag (ab002-100; Multi Sciences, Hangzhou, China), and GAPDH (60004-1-Ig; Proteintech, Rosemont, IL, USA).

\section{Flow cytometry}

Cells were fixed with $70 \%$ ethanol at $-20{ }^{\circ} \mathrm{C}$ overnight and washed three times with cold PBS. The samples were stained with PI/RNase Staining Buffer (BD Pharmingen, Franklin Lakes, NJ, USA) for $15 \mathrm{~min}$ at room temperature according to the manufacturer's instructions. Stained cells were analyzed with a BD FACSCanto II Flow Cytometer. The results were analyzed using ModFit LT 3.1.

\section{Nuclear protein and cytoplasmic protein extraction}

After the cells were washed with PBS, they were scraped off with a cell scraper and collected by centrifugation to leave a cell pellet. After extraction of the nucleus and cytoplasm using a Nuclear and Cytoplasmic Protein 
Extraction Kit (Beyotime Biotechnology, Wuhan, China) western blotting was performed.

\section{LC-MS/MS identification of proteins}

Cells were lysed in RIPA Lysis Buffer $(50 \mathrm{mM}$ Tris $\mathrm{pH}$ 7.4, $120 \mathrm{mM} \mathrm{NaCl}, 1 \%$ Triton X-100, $1 \%$ sodium deoxycholate, $0.1 \%$ SDS, Beyotime, China) supplemented with protease inhibitors (Complete Mini, Roche, Switzerland) and phosphatase inhibitors (PhosSTOP, Roche, Switzerland). Then, $1000 \mu \mathrm{g}$ of total cell lysates were incubated with $1 \mu \mathrm{g}$ of primary antibody or control rabbit IgG at $4{ }^{\circ} \mathrm{C}$ overnight. Then, $20 \mu \mathrm{L}$ of Protein $\mathrm{A}+\mathrm{G}$ agarose (Bioworld Technology, USA) was added for $2 \mathrm{~h}$ at $4{ }^{\circ} \mathrm{C}$ with rocking. The precipitates were washed four times with RIPA lysis buffer (50 mM Tris pH 7.4, $150 \mathrm{mM} \mathrm{NaCl}, 1 \% \mathrm{NP}-40,0.5 \%$ sodium deoxycholate, $0.1 \%$ SDS, Beyotime, China).

Analysis was conducted on a Q Exactive mass spectrometer coupled to an Easy nLC (Thermo Fisher Scientific, USA) using a routine method. MS data were acquired using a data-dependent top 10 method dynamically selecting the most abundant precursor ions from the survey scan $(300-1800 \mathrm{~m} / \mathrm{z})$ for HCD fragmentation. The proteins identified from the blank control group were regarded as non-specific proteins and were removed from the protein list identified from the MCCC2 test group to exclude the non-specifically binding proteins of MCCC2.

\section{Wound healing assay}

Cells were seeded into six-well plates and transfected as previously described. After the cells were cultured to $90 \%$, a line was gently etched on the bottom with a $100 \mu \mathrm{L}$ perpendicular tip. The lines were made as straight as possible. Excess cellular debris was removed with cell PBS (Hyclone, USA). Then, serum-free medium was added to incubate the cells at $37{ }^{\circ} \mathrm{C}$. The lines were photographed using a Nikon confocal microscope (Nikon, NY, USA) at 0,24 , and $48 \mathrm{~h}$.

\section{Transwell assays}

Transwell assays were conducted in 24-well plates to investigate the invasiveness of the tumor cells. Cells were resuspended in serum-free medium and seeded into the upper chamber. There were approximately $1 \times 10^{5}$ cells in each upper chamber. According to the manufacturer's instructions, we prepared and used Matrigel. The bottom chamber was filled with $500 \mu \mathrm{L}$ of medium containing 10\% FBS. The cells were then incubated at $37^{\circ} \mathrm{C}$ for $24 \mathrm{~h}$. After incubation in xylene for $1 \mathrm{~h}$ and staining with crystal violet. The cells were wiped inside the room with a cotton swab. A microscope was used to observe and take pictures.

\section{Xenograft mouse model}

Nude mice were obtained from the Nantong University Laboratory Animal Center. SMMC-7721 cell suspension in DMEM $\left(5 \times 10^{6}\right.$ /mouse, $\left.\mathrm{n}=3\right)$ was subcutaneously injected into the male nude mice. Mice were euthanized eight weeks after implantation, and tumor xenografts were collected.

\section{Immunocytofluorescence (IF)}

Cells were fixed with $4 \%$ paraformaldehyde in PBS for $1 \mathrm{~h}$ at room temperature then permeabilized with $1 \%$ Triton X-100 in PBS for 20 min. The cells were blocked with $1 \%$ BSA in PBS for $1 \mathrm{~h}$ and incubated with primary antibodies overnight at $4{ }^{\circ} \mathrm{C}$. Secondary antibody incubation was performed using Alexa Fluor 568 donkey anti-mouse or Alexa Fluor 488 donkey anti-rabbit antibodies (Invitrogen, Carlsbad, CA, USA) for $1 \mathrm{~h}$ at room temperature. Then, $5 \mathrm{mg} / \mathrm{mL}$ DAPI was added to stain the nucleus. The slides were mounted and visualized using a Nikon confocal microscope (Nikon, Melville, NY, USA).

\section{Lactate and glucose measurements}

Briefly, glucose concentrations in the media were determined using a glucose colorimetric assay kit (BioVision, Milpitas, CA, USA) and lactate secretion was determined using a lactate colorimetric assay kit (BioVision) following the manufacturer's instructions.

\section{Total RNA extraction and quantitative real-time polymerase chain reaction (RT-qPCR)}

RNA extraction and real-time RT-PCR were performed as previously described [7]. All primers were purchased from Sangon (Shanghai, China). Primer sequences were as follows: GLUT1 forward: 5'-CAGTTTGGC TACAACACTGGAG-3'; GLUT1 reverse, 5'-GCCCCC AACAGAAAAGATGG-3'; LDHA forward: $5^{\prime}-$ TGG AGATTCCAGTGTGCCTGTATGG-3'; LDHA reverse: 5'- CACCTCATAAGSACTCTCAACCACC-3'; LDHB forward: 5'-GGAAGGAAGTGCATAAGATGGTGG-3'; LDHB reverse: $5^{\prime}$-CCCCTTTACCATTGTTGACACG3'; GAPDH forward: 5'-AGAAGGCTGGGGCTCATT TG-3'; GAPDH reverse: 5'-AGGGGCCATCCACAG TCTTC-3'.

\section{Acetyl-CoA ratio measurement assay}

Briefly, AcCoA content was determined from total or cytosolic fractions using the acetyl-CoA assay kit (ab87546, Abcam) according to the manufacturer's instructions. 


\section{Statistical analysis}

All data were analyzed and displayed using GraphPad 8.0.2 (GraphPad Software, Inc., La Jolla, CA, USA). Student's t-test analysis was used to analyze differences between groups. The Kaplan-Meier method was used to analyze the survival curves. For all tests, a P-value of less than 0.05 was considered statistically significant.

\section{Results}

MCCC2 is upregulated in HCC and predicts a poor prognosis for $\mathrm{HCC}$ patients

Although MCCC1 and MCCC2 are involved in the catabolism of leucine, their roles in the development of HCC are largely unknown. In this study, TCGA dataset with an online program (https://www.gepia.cancer-pku. cn) [26] was used to explore the correlation between HCC patient survival and the expression of MCCC1 and MCCC2. Interestingly, we found that high expression of MCCC2 but not MCCC1 predicts a poor prognosis in HCC patients (Fig. 1a). Next, we examined the expression of MCCC2 in cell lines by western blotting. Compared to normal liver LO2 cells, the expression of MCCC2 in SMMC-7721 and HepG2 was largely increased at the protein level (Fig. 1b). However, the expression of MCCC2 in SK-HEP-1 cells was undetectable. Similar results were observed at the RNA level (Fig. 1c). Collectively, these results suggest that MCCC2 may play an important role in the progression of $\mathrm{HCC}$.

\section{MCCC2 regulates HCC cell proliferation, migration, and glycolysis in vitro}

Next, we explored the role of MCCC2 in the biological behavior of HCC cells. Based on the expression of MCCC2 in HCC cell lines, SMMC-7721 cells were transfected with sgRNA and the stable cell line was successfully established (Fig. 2a). As shown in Fig. 2a, sgMCCC2-1 and MCCC2-2 with the best knockdown effect were selected for subsequent experiments. Next, we detected the expression of tumor markers in SMMC7721 cells after knocking down MCCC2. We found that
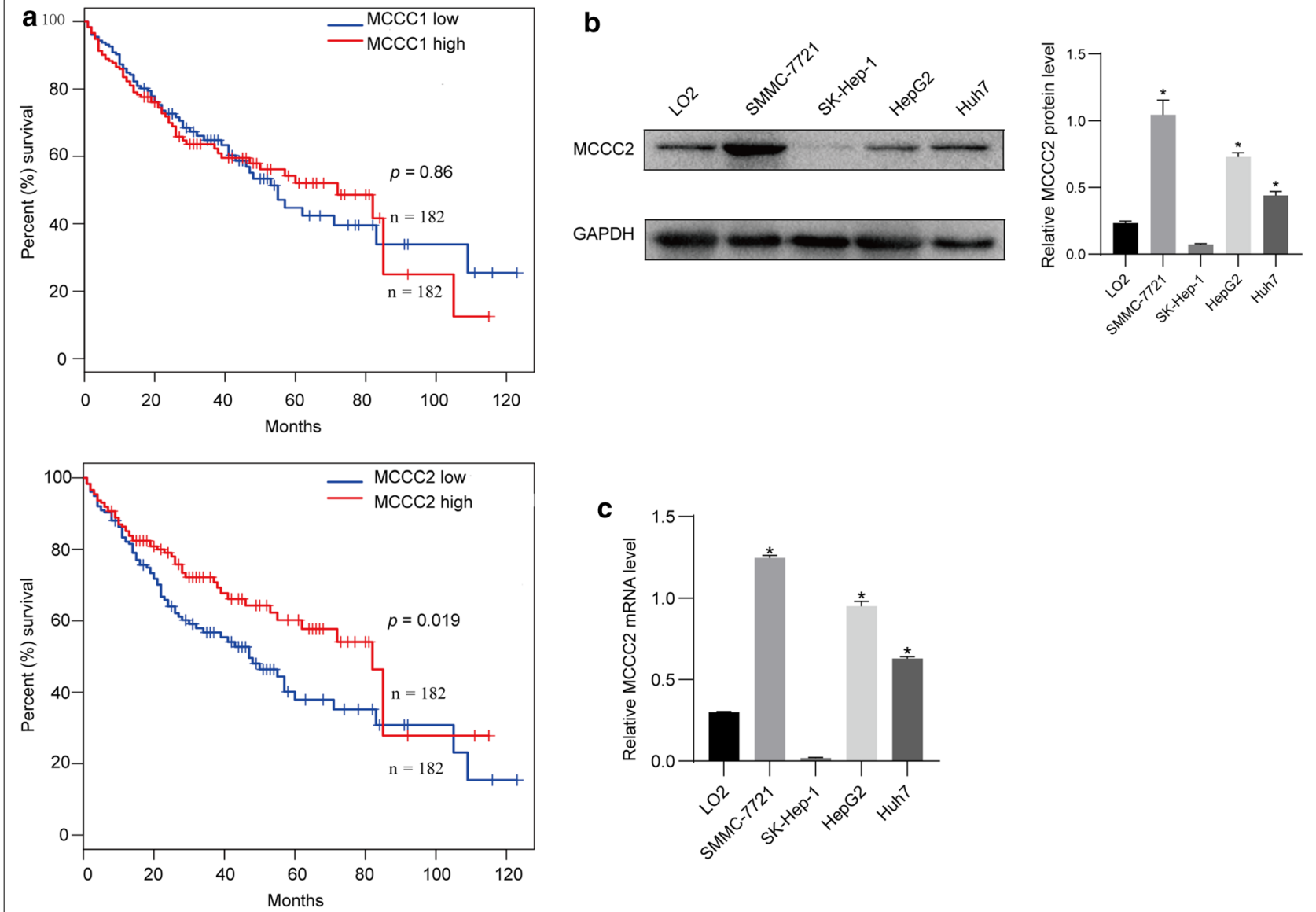

Fig. 1 The expression of MCCC2 is upregulated and predicts a poor prognosis in HCC. a TCGA database were used to analyze the relationship between the expression of MCCC 1 and MCCC 2 and the survival rate in HCC patients. $\mathbf{b}$ Western blot images demonstrated the expression of MCCC2 in HCC cell lines and the normal liver cells. cThe expression of MCCC2 in HCC cell lines and the normal liver cells was detected by qRT-PCR 
the expressions of tumor proliferation-related markers PCNA and C-myc were reduced in SMMC-7721 cells transfected with sg-MCCC2-1 and sg-MCCC2-3 and found that the expression of $\mathrm{N}$-cadherin, a mesenchymal cell-specific marker, decreased. However, knockdown of MCCC2 could upregulate the expression of E-cadherin, an epithelial cell marker. Simultaneously, we found that the invasion-related marker MMP9 expression was reduced in MMC-7721 cells transfected with sg-MCCC2-1 and sg-MCCC2-3 (Fig. 2b). These results suggest that MCCC2 plays an important role in cell metastasis and the invasion of $\mathrm{HCC}$.

Interestingly, $\mathrm{CCK}-8$ and clone formation experiments proved that knockdown of MCCC2 expression significantly inhibited cell proliferation compared with the control cells (Fig. 2c, e). Flow cytometric analysis revealed that SMMC-7721 cells transfected with sgRNA were arrested in the $\mathrm{S}$ phase (Fig. $2 \mathrm{f}, \mathrm{g}$ ). In addition, the scratch-wound healing assay and Transwell assay showed that knockdown of MCCC2 reduced the migration and invasion ability of SMMC-7721 cells (Fig. 2h, k). As described above, MCCase is involved in leucine metabolism, thus, we investigated whether MCCC2 regulates amino acid metabolism. As expected, the expression of Glut1, LHDA, and LHDB, which are glycolysis markers, decreased in SMMC-7721 cells transfected with sgMCCC2-3 (Fig. 2l), and glucose consumption and lactate secretion also decreased (Fig. 2l-n). In summary, our results indicated that $\mathrm{MCCC} 2$ plays a critical role in cell proliferation, migration, invasion, and glycolysis in HCC cells in vitro.

\section{MCCC2 promotes HCC cell proliferation in vivo}

To further explore whether knockdown of MCCC2 also affects the tumor formation of $\mathrm{HCC}$ cells in vivo, SMMC-7721 cells stably transfected with sg-MCCC2-3 or control vector were injected subcutaneously into nude mice. After six weeks, the subcutaneous tumors were smaller in the sg-MCCC2-3 group than in the control group (Fig. 3a, b). Moreover, the tumor weight in the sg-MCCC2-3 group was significantly lower than that in the control group (Fig. 3c). Therefore, our results demonstrate that knockdown of MCCC2 inhibits tumor growth in vivo.

\section{Cytoplasmic distribution of MCCC2 in HCC cells}

To further explore the role of $\mathrm{MCCC} 2$, we examined the localization of MCCC2 in HCC cells. By separating the nuclear and cytoplasmic fractions of SMMC-7721 cells, we found that MCCC2 was mainly distributed in the cytoplasm (Fig. 4a). The cytoplasmic distribution of MCCC2 in HCC cells was further confirmed by immunofluorescence experiments (Fig. 4b). This is consistent with the localization of MCCC2 on mitochondria and its function in amino acid metabolism.

\section{The oncogenic function of MCCC2 in HCC cells is dependent on leucine}

MCCC2 can affect leucine metabolism [27]. It is not currently known whether the oncogenic function of MCCC2 is also associated with leucine metabolism. To examine the effect of leucine on HCC cells, SMMC7721 cells were cultured with leucine-free medium and it was found that the proliferation, migration, and invasion capabilities of SMMC-7721 cells were significantly reduced compared with the control cells (Fig. 5a, g). This suggested that SMMC-7721 cells were largely dependent on the presence of leucine in culture. Interestingly, we found that SK-HEP-1 cells, which lack the expression of MCCC2 (Fig. 1b, c), failed to respond to leucine deprivation. MCCCs can decompose leucine into acetylCoA [27], which is the final product of leucine metabolism. Meanwhile, the level of acetyl-CoA significantly decreased in SMMC-7721 cells transfected with sgMCCC2-3 compared to in control cells (Fig. 5h). These results suggest that $\mathrm{HCC}$ cells with the expression of MCCC2 are dependent on leucine.

\section{Leucine deprivation failed to inhibit HCC cell growth in MCCC2 knockdown cells}

To further examine the dependence of MCCC2 on leucine, we investigated the effect of leucine deprivation in SMMC-7721 cells transfected with sg-MCCC2. Interestingly, we found that the cell viability of SMMC-7721 cells

\footnotetext{
(See figure on next page.)

Fig. 2 MCCC2 promotes the proliferation, migration, and invasion of HCC cells. a The expression of MCCC2 was determined using western blot after transfection. $\mathbf{b}$ Western blot analysis was used to detect the relative protein levels of MCCC2, PCNA, c-Myc, N-cadherin, N-cadherin, and MMP9 in the MCCC2 low expression group and control group for SMMC-7721 cell lines. c SMMC-7721 cells were transfected with vector sg-MCCC2 to examine the proliferation of SMMC-7721 cells by CCK-8 assay. $\mathbf{d}$, e The cells were transfected and seeded into six-well plates for $2 \mathrm{~W}$. $\mathbf{f}$, $\mathbf{g}$ Flow cytometry was performed to determine the cell cycle distribution of the cells that were transfected. The cell cycle distribution is displayed in the bar chart. h, i Wound-healing assay. HCC cells were transfected with sg-MCCC2 and vector. The wound was observed at 0, 24 , and 48 h under a light microscope. j, k Transwell assay. Cells transfected with sg-MCCC2 and vector travelled membrane were observed at $48 \mathrm{~h}$. I qrt-PCR was used to detect Glut1, LHDA, and LHDB expression in the MCCC2 low expression and control groups for SMMC-7721 cell lines. $\mathbf{m}, \mathbf{n}$ Glucose and lactate consumption was detected in the same groups
} 

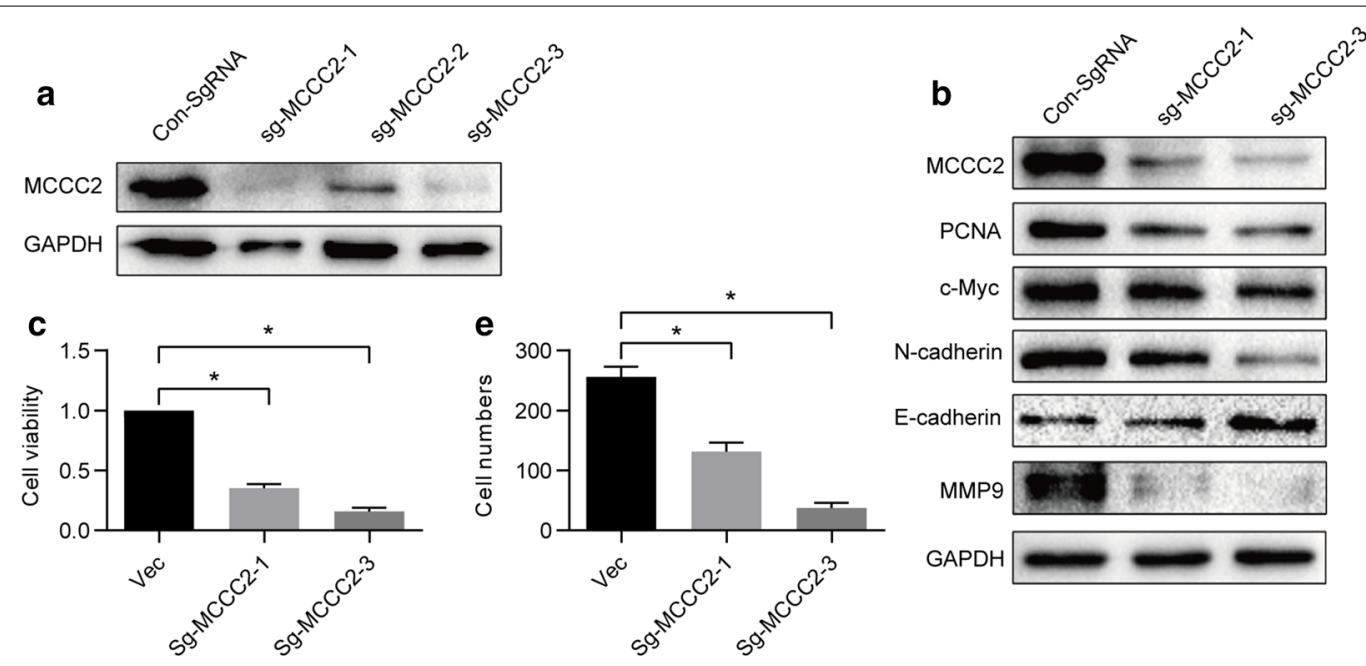
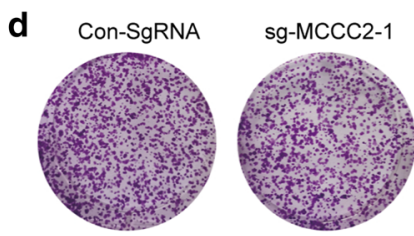

h
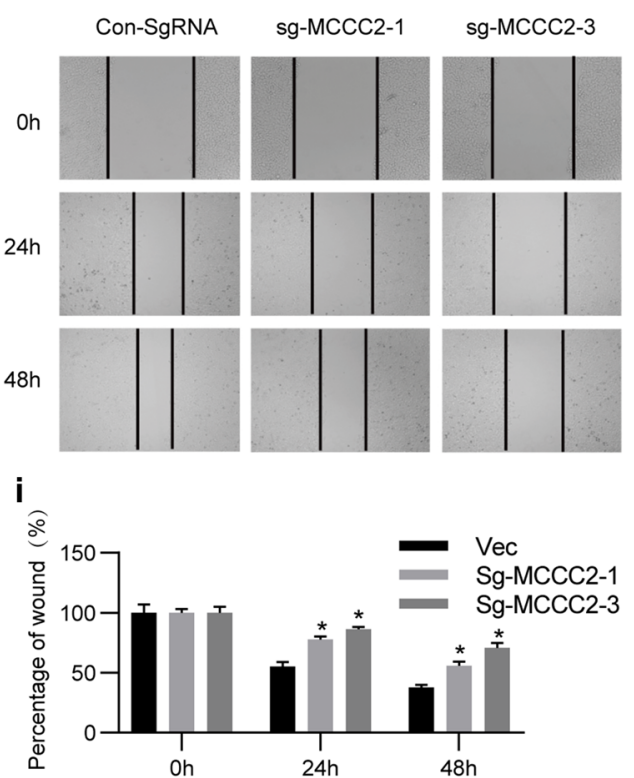

$$
\text { I }
$$
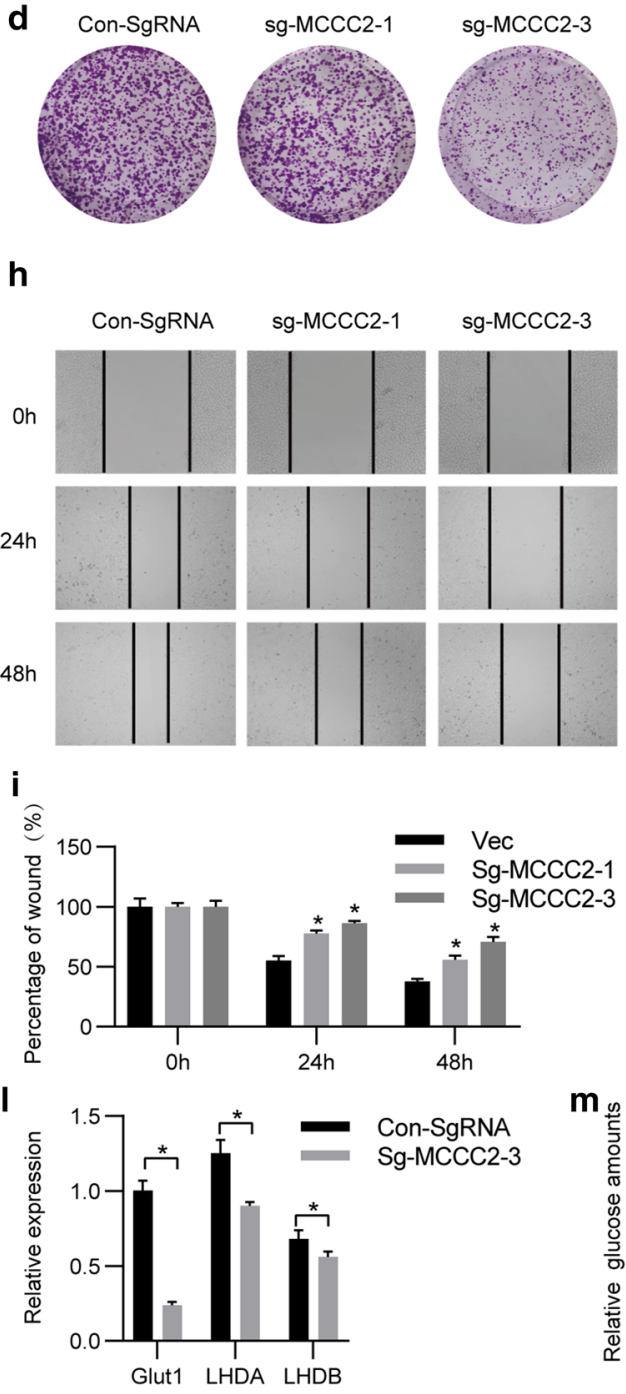

f Con-SgRNA sg-MCCC2-1 sg-MCCC2-3

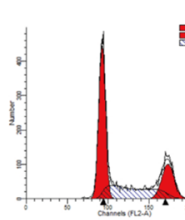

g
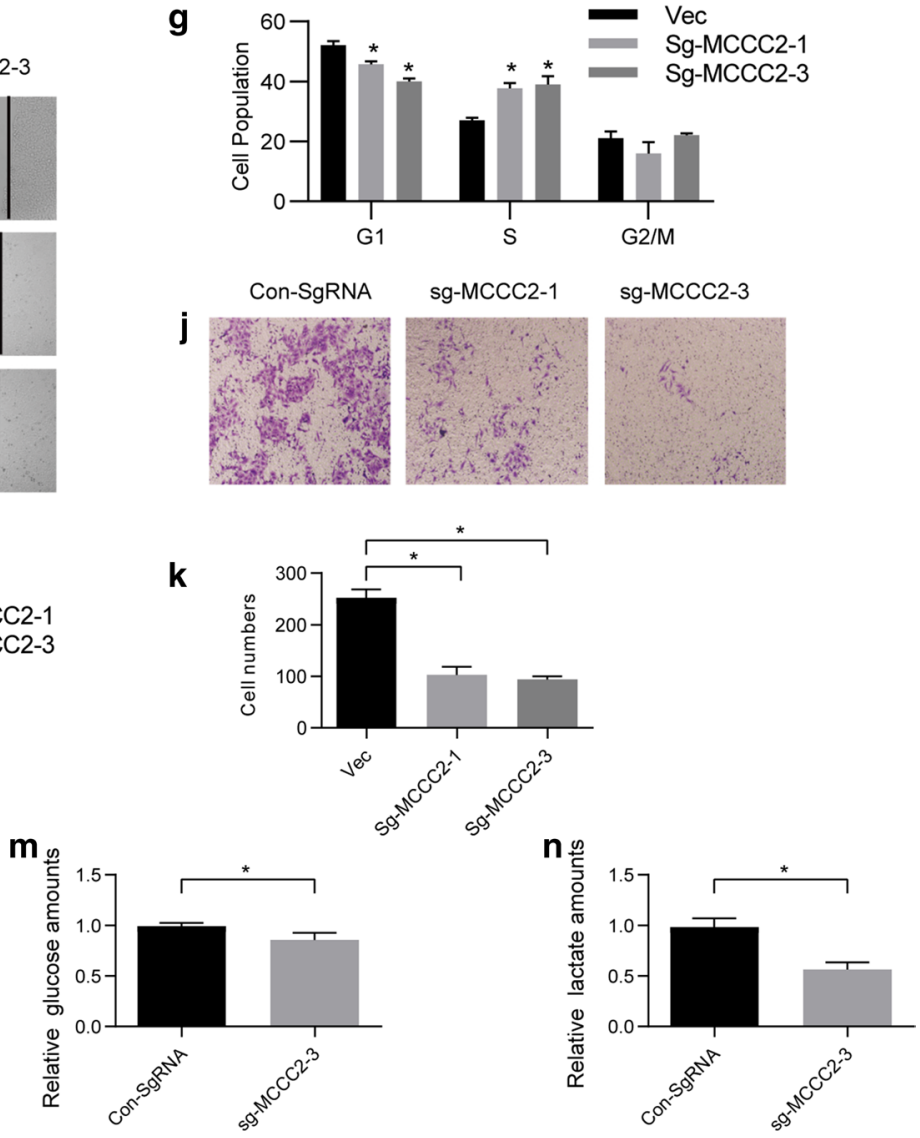

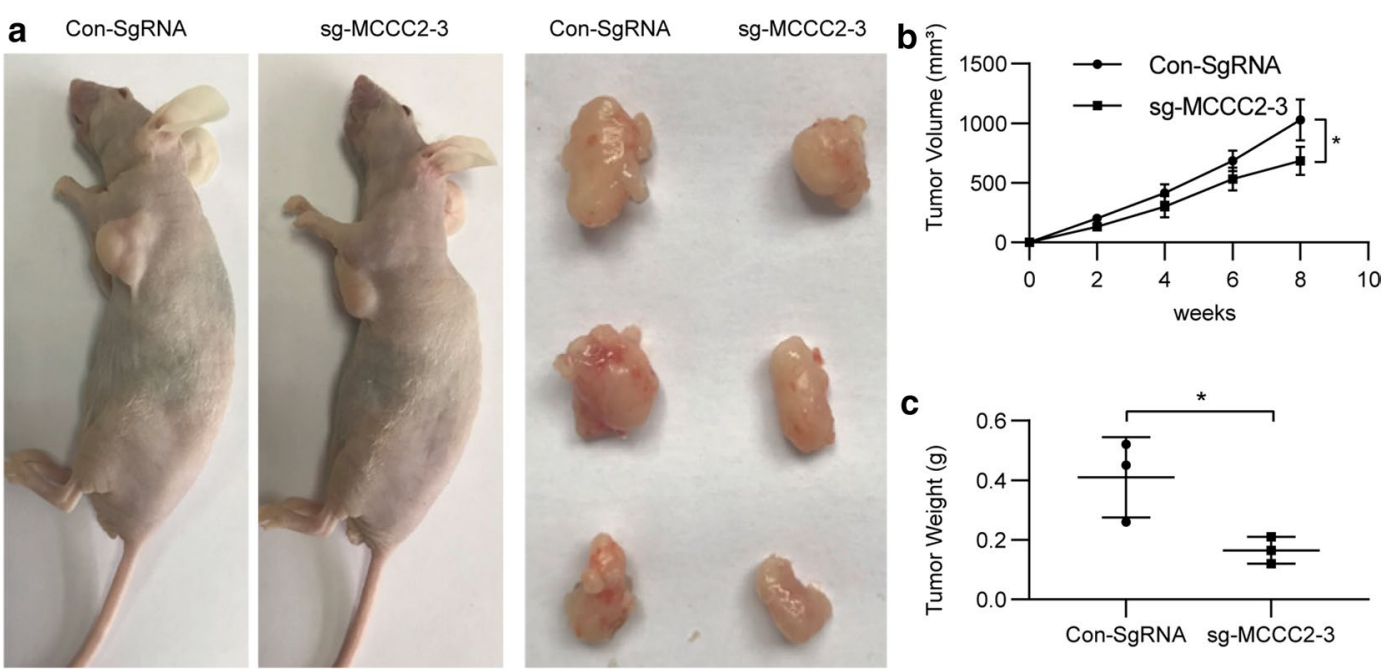

Fig. 3 MCCC2 promotes HCC growth in vivo. a Xenograft tumors were generated by subcutaneously injecting SMMC-7721 cells knocking down MCCC2 or carrying a control vector. $\mathbf{b}$, $\mathbf{c}$ The xenograft tumor weight was recorded. All ${ }^{*} \mathrm{P}<0.05$

\begin{tabular}{|l} 
Cytoplasm \\
Fig. 4 MCCC2 is distributed in the cytoplasm of HCC cells. a Western blot analysis of cytoplasmic and nuclear distribution of MCCC2. GAPDH and \\
H3 in SMMC-7721 cell were used as specific markers for cytoplasmic and nuclear components, respectively. b Immunofluorescence analysis of \\
MCCC2 in SMMC-7721 cells using anti-MCCC2 antibodies
\end{tabular}

transfected with sgRNA vector greatly decreased upon leucine deprivation. However, there were no differences in SMMC-7721 cells transfected with sg-MCCC2 with or without leucine (Fig. 6a). Similar results were found in the cell proliferation, migration, and invasion abilities of SMMC-7721 cells through colony formation experiments (Fig. 6b, c), scratch-wound healing assay (Fig. 6d, e), and Transwell experiment, respectively (Fig. 6f, g). Taken together, these findings indicate that the effect of leucine deprivation on HCC cells is dependent on MCCC2.

\section{MCCC2 promotes ERK activation in HCC cells}

Previous studies have shown that EGF activates the PI3K/ AKT pathway and promotes leucine uptake by prostate cancer cells, thereby promoting tumor development [28]. To decipher the underlying mechanisms of MCCC2 in HCC, we also detected the activation of MEK and ERK. We found that the activation of MEK and ERK was greatly reduced in SMMC-7721 cells transfected with
sg-MCCC2 (Fig. 7a). Furthermore, overexpression of MCCC2 in Hek-293T cells could induce the activation of MEK and ERK (Fig. 7b). Therefore, our results indicate that MCCC2 can promote ERK activation, which is a common oncogenic pathway frequently observed in cancer cells.

\section{The profiling of MCCC2 binding proteins and their associated pathways}

Our results demonstrated a critical role of MCCC2 in HCC cells and the association between MCCC2 and leucine. To fully understand the molecular mechanism and the binding proteins of MCCC2 in HCC cells, an immunoprecipitation assay was carried out using an anti-MCCC2 antibody. Subsequently, mass spectrometry was employed to identify the MCCC2-associated protein (Additional file 1). The top 50 proteins from the IPmass spectrometry data were listed in Fig. 8a). Through protein mass spectrometry analysis, we identified 461 

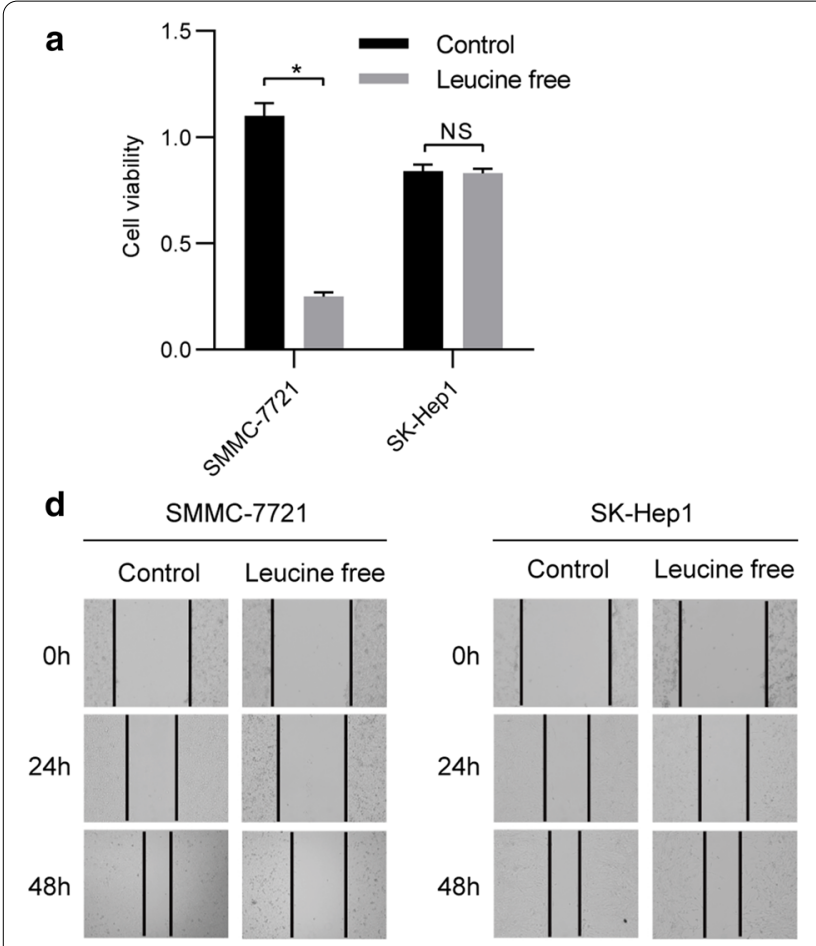

b

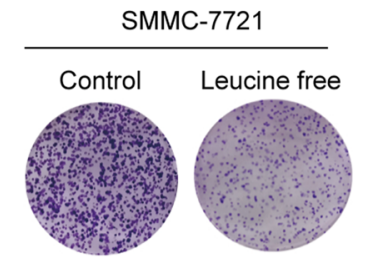

C

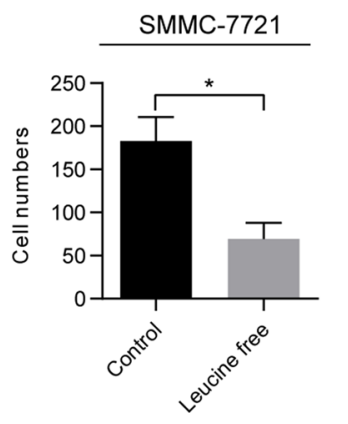

f
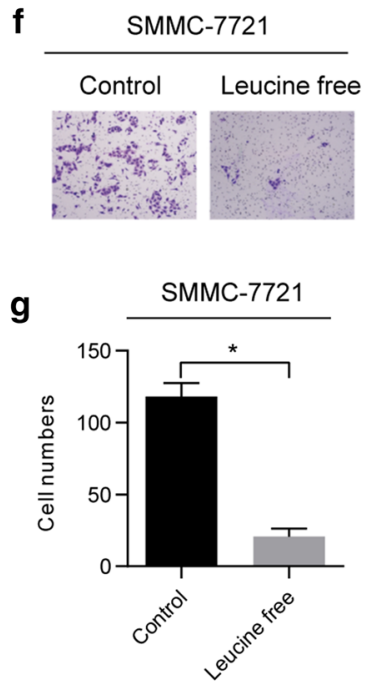
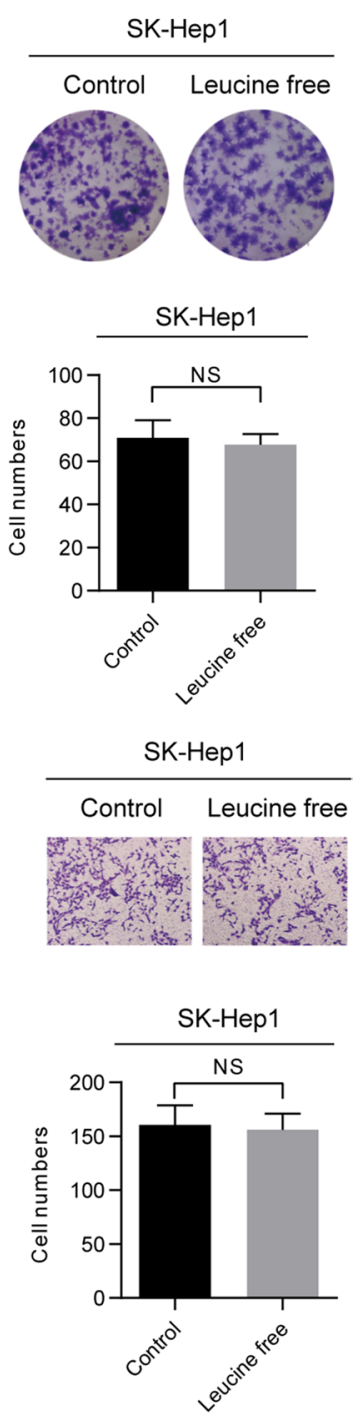
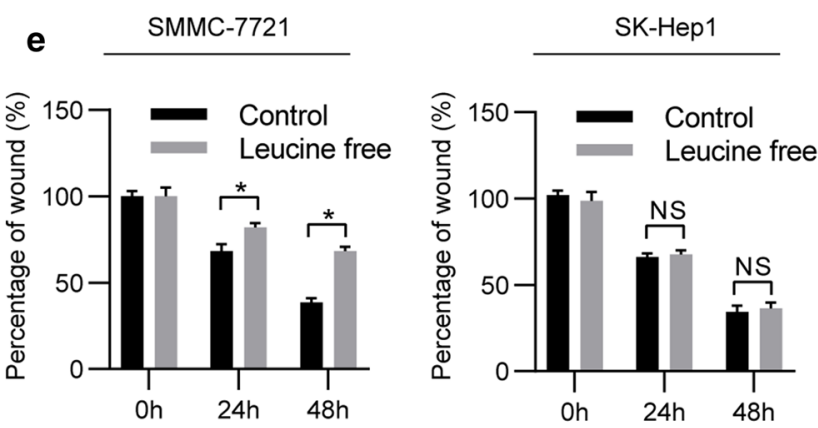

h

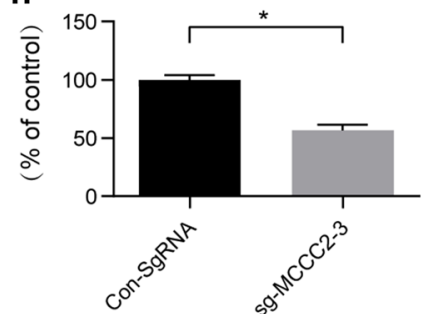

Fig. 5 Absence of leucine fails to inhibit the biological characteristics of the HCC cells. a The following experiments were carried out in SMMC-7721 cell lines with relatively high MCCC2 expression and SK-Hep1 cell lines with no MCCC2 expression. The same number of cells were plated in 96-well plates and cultured under normal or leucine ${ }^{-}$conditions, and the number and viability of cells were determined every day by CCK-8 assay. b-g Colony-formation, Wound-healing, and Transwell assays were performed with SMMC-7721 and SK-Hep1 cells treated as described above. $\mathbf{h}$ Acetyl-CoA levels were assessed with the knockdown of MCCC2 in SMMC-7721 cells

proteins with at least six unique peptides with high confidence. To further understand the functional significance, the identified proteins were classified according to biological process, molecular function, and cellular component. The main biological processes of these associated proteins are enriched in protein metabolism, energy 

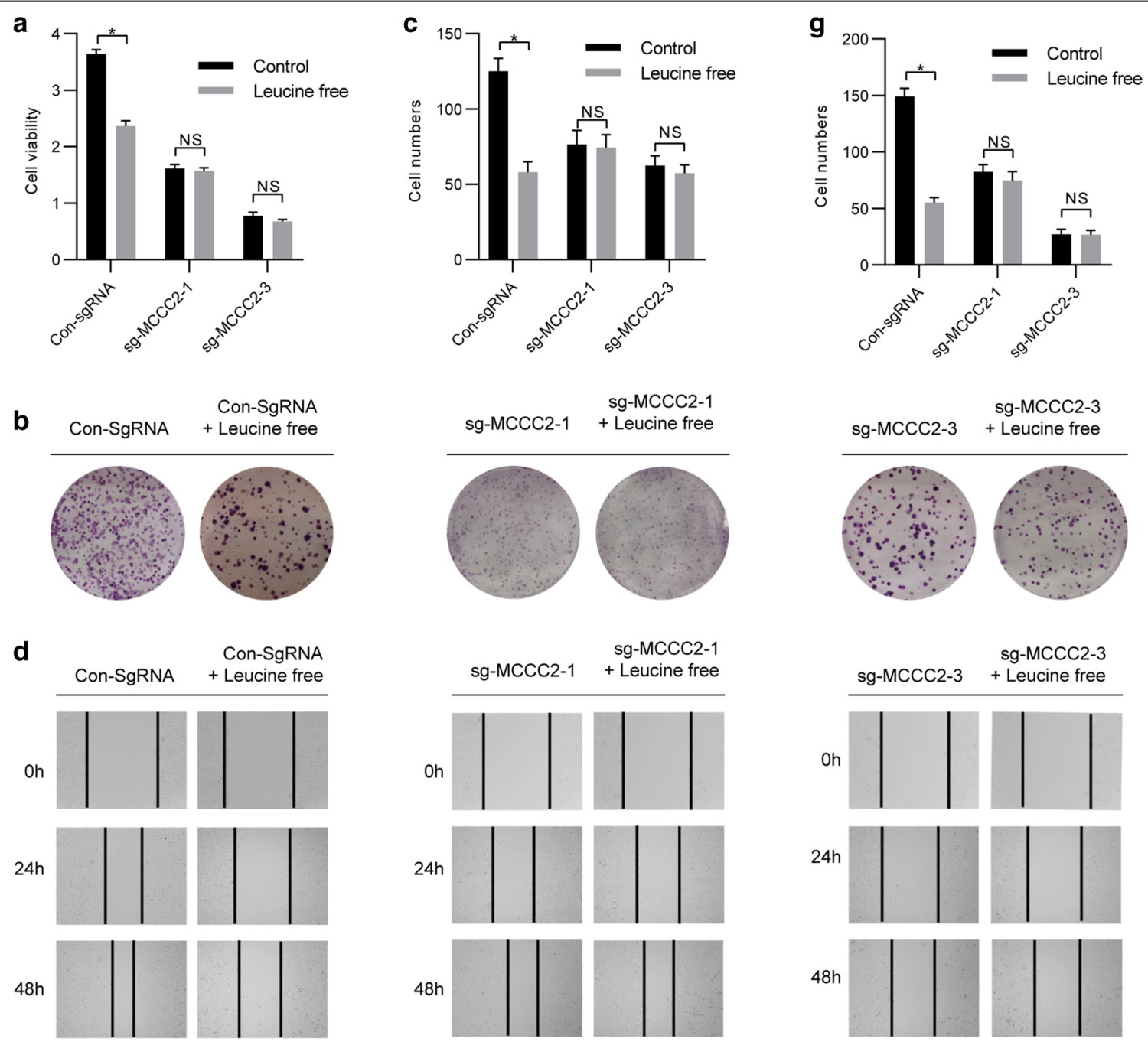

e
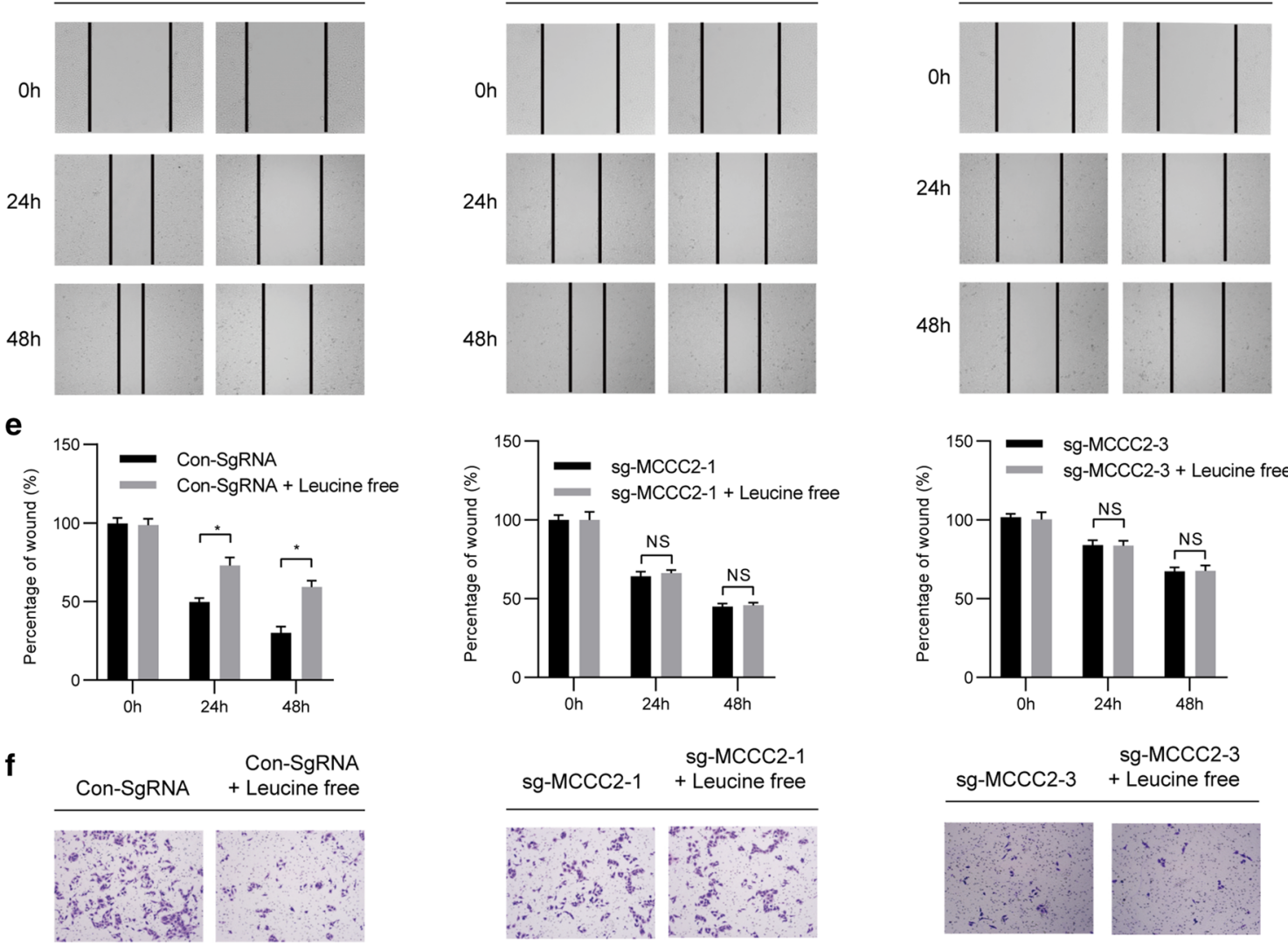

Fig. 6 After MCCC2 knockdown, absence of leucine failed to inhibit the biological characteristics of SMMC-7721 cells. a Sg-MCCC2 and vector plasmids were stably infected into SMMC-7721 cells. The same number of cells was plated into 96-well plates and cultured under normal or leucine-free ${ }^{-}$conditions, and the number and viability of the cells were determined every day by CCK-8 assay. $\mathbf{b}-\mathbf{g}$ Colony-formation, Wound-healing, and Transwell assays were performed with SMMC-7721 cells treated as described above 
a
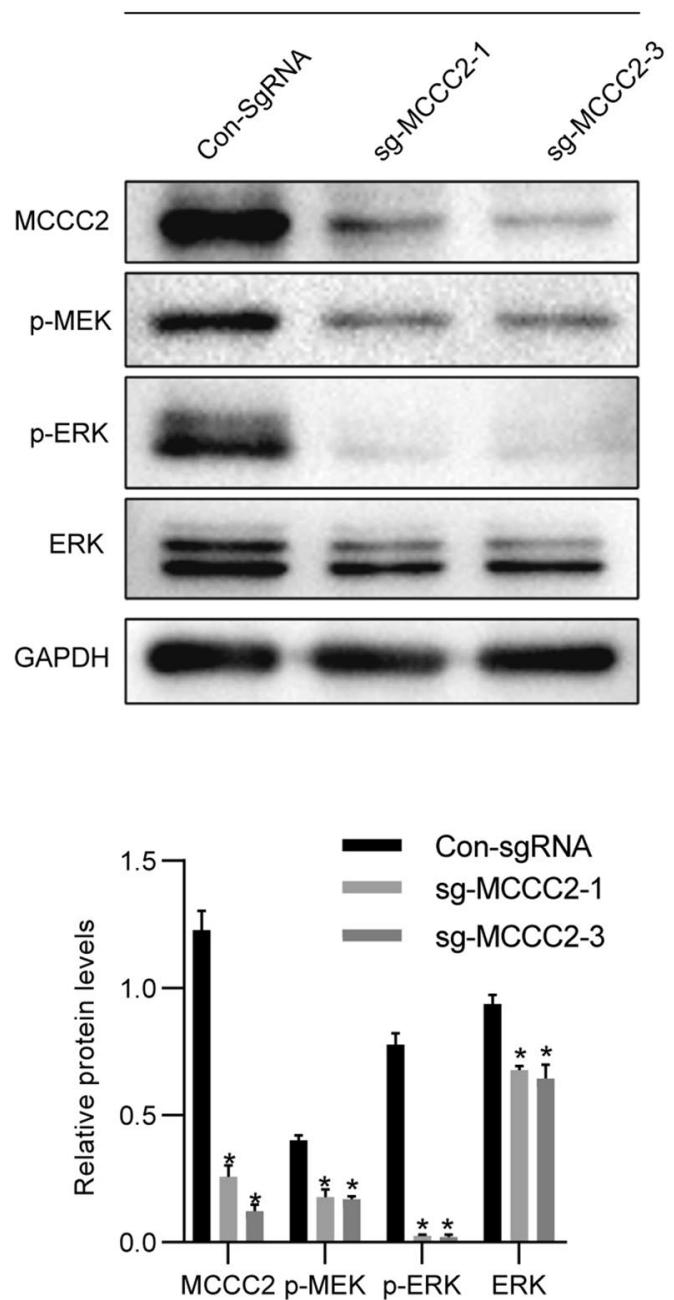

b
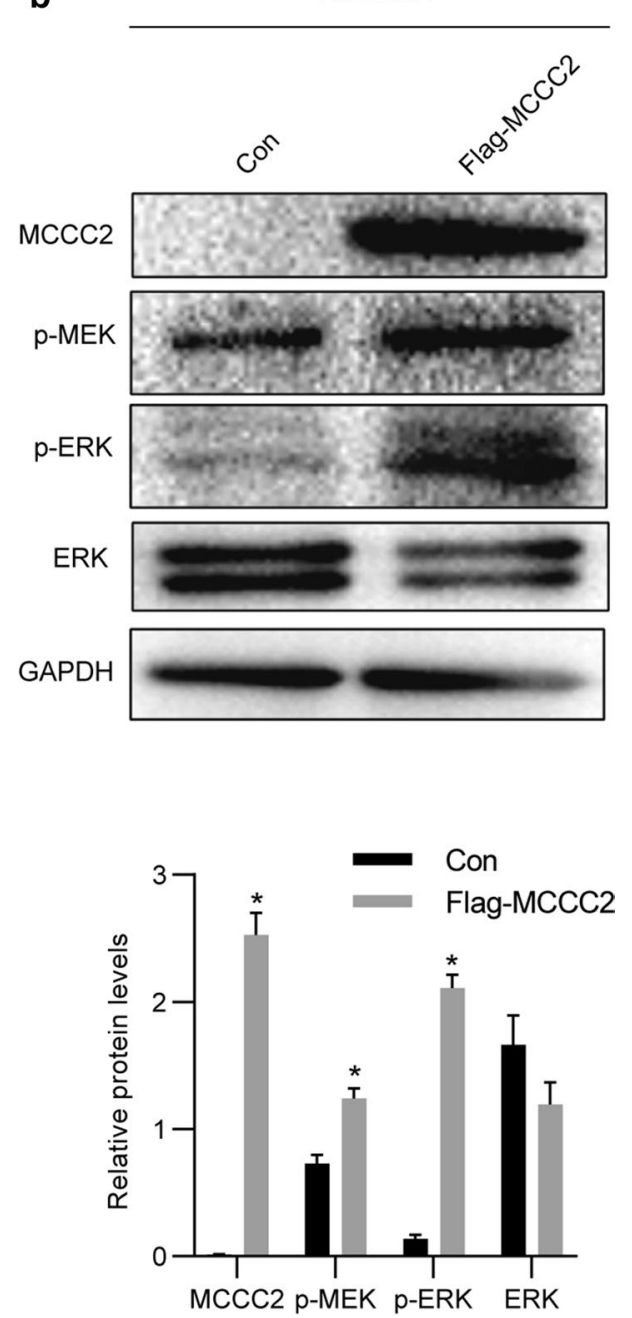

Fig. 7 MCCC2 promotes ERK activation. a SMMC-7721 cells were transfected with sg-MCCC2 or vector and directly lysed followed by western blot analysis. b 293T cells were transfected with Flag-MCCC2 or control and directly lysed followed by western blot analysis

pathways, and metabolism (Fig. 8b). Therefore, MCCC2 may play an important role in these processes, thereby affecting the occurrence and development of HCC. However, the individual associated proteins identified by IP-MS require further investigation.

\section{Discussion}

At present, the clinical treatment of HCC is largely based on surgical resection and chemotherapy, which has many restrictions and often leads to unsatisfactory results [29]. For the treatment of advanced HCC, only the multikinase inhibitor sorafenib has been approved for clinical targeted therapy [30]. Recently, another new multi-kinase inhibitor, regorafenib, and an anti-PD-1 antibody, nivolumab, were established as a new generation of drugs for the treatment of advanced HCC. However, patient prognosis remains poor [31]. Furthermore, the number of potential targets in the preclinical development of HCC therapy is currently very limited. Therefore, there is an urgent need to identify more druggable targets. In this study, we found that MCCC2 plays an important role in HCC. After knocking down MCCC2, the proliferation, migration, and invasion ability of HCC cells significantly decreased. Mechanistically, MCCC2 plays an oncogenic role, at least partially, by regulating the leucine metabolism pathway. Tumor cells often upregulate the uptake of leucine to support cancer development [7, 32]. Besides abnormal uptake of leucine, the enhanced leucine metabolism pathway, such as the upregulation of MCCC2, might also be a critical method of utilizing leucine for cancer growth. Therefore, targeting enzymes involved in leucine metabolism, such as MCCC2, might be a potential method of treating cancer, including HCC. 


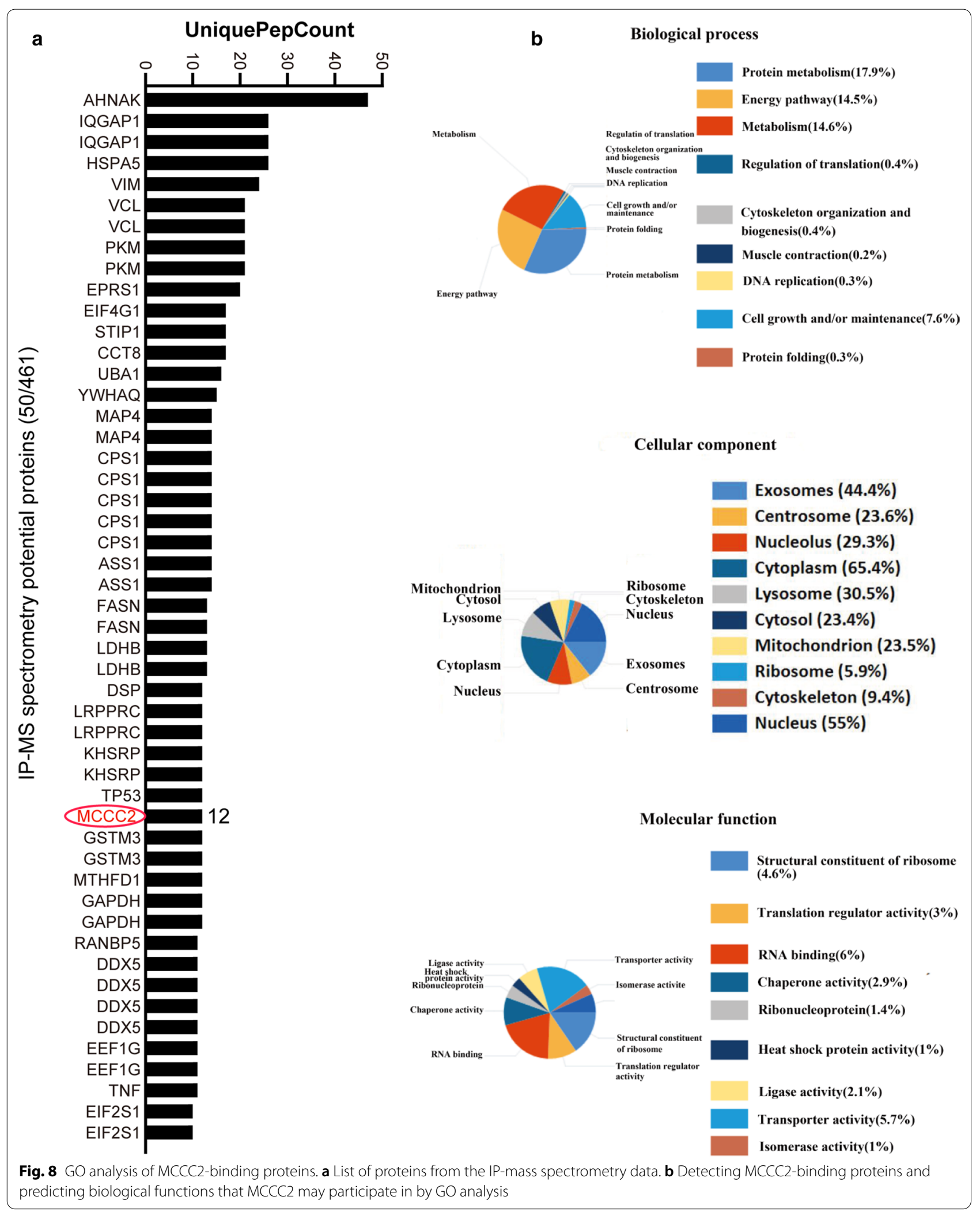


As an essential amino acid (EA), leucine can only be obtained from diet or microorganisms in mammals $[33,34]$. The other 11 amino acids that can be synthesized directly in mammalian cells become nonessential amino acids (NEAAs) [35]. To continue to proliferate, cancer cells require AAs. In the process of transformation, cancer cells develop an abnormal ability to survive and proliferate. These transformed cancer cells are different from normal cells, and in some cases, they rely on specific conditions or specific AAs for survival. In our experimental system, tumor cells were sensitive to leucine deprivation in the external environment (Figs. 5 and 6 and a-d, left column). This observation is consistent with the fact that leucine metabolism is altered in many solid tumors and leucine is needed as a fuel for cancer growth [36]. After knocking down MCCC2, cells become less sensitive to the externally available leucine (Figs. 5 and 6 and a-d, middle and right column). This suggests that cancer cells use key genes to upregulate survival-dependent leucine metabolism. Disruption of these key genes can restore leucine metabolism and make cancer cells less dependent on leucine. Such a mechanism has clinical implications that cancer cells might change drug sensitivity when the oncogenic pathways are changed during cancer development.

We investigated the molecular mechanism by which MCCC2 regulates leucine metabolism as well as other oncogenic functions. To systematically identify the MCCC2-associated proteins, we used IP mass spectrometry to detect potential proteins that interact with MCCC2 in tumor cells. The proteins associated with MCCC2 are enriched in protein metabolism, energy pathways, and metabolism. This is consistent with the function of MCCC2 in leucine metabolism. Among the identified proteins, GCN1 is one of the most interesting. GCN1 is an eIF-2-alpha kinase activator that can activate eIF $2 \alpha$-related pathways. This pathway can affect the utilization of amino acids in colorectal cancer [37]. In addition, the activation of eIF2 $\alpha$ caused by the GCN1/GCN20 complex can promote the translation of a large number of proteins [38]. These functions of GCN1 support the observations of this study. It is likely that MCCC2 is also associated with GCN1 and subsequently activates eIF $2 \alpha$-related pathways, thereby affecting the uptake and utilization of amino acids. However, these predictions require experimental validation in future.

In summary, results from in vitro and in vivo experiments support the critical function of MCCC2 in HCC. MCCC2 may regulate leucine metabolism to promote HCC. MCCC2 and its related leucine pathway may be interesting targets for cancer therapy. Therefore, we not only identified a potential target for molecular therapy, but also delineated the important role of leucine in the tumor environment in this study.

\section{Conclusions}

MCCC2 might promote HCC development by supporting leucine oncogenic function.

\section{Supplementary Information}

The online version contains supplementary material available at https://doi. org/10.1186/s12935-020-01722-w.

Additional flie 1. The MCCC2-associated proteins identified by IP-MASS spectrometry.

\section{Abbreviations}

MCCC2: Methylcrotonoyl-CoA carboxylase 2; HCC: Hepatocellular carcinoma; DMEM: Dulbecco's modified Eagle's medium; MCC: 3-Methylcrotonyl-CoA carboxylase; CST: Cell signaling technology; EA: Amino acid; NEAA: Non-essential amino acids.

\section{Acknowledgements}

This work was supported by grants from the Social Development Foundation of Nantong City (Grant Nos. JC2019032; MS12019020), the Key Research and Development Plan of Jiangsu Province (No. BE2019692); the Postdoctoral Science Foundation of China (Grant No. 2019M661909); and the Young Medical Talent Project of Jiangsu Province (QNRC2016697).

\section{Authors' contributions}

LSQ and WH conceived and designed the experiments. YYC, CZX, and XNZ participated in the experiments and drafted the manuscript. DHZ and JC contributed to sample collection and interpretation of the data. YS performed the statistical analysis. All authors read and approved the final manuscript.

\section{Funding}

This work was supported by grants from the Social Development Foundation of Nantong City (Grant Nos. JC2019032; MS12019020), the Key Research and Development Plan of Jiangsu Province (No. BE2019692); the Postdoctoral Science Foundation of China (Grant No. 2019M661909); and the Young Medical Talent Project of Jiangsu Province (QNRC2016697).

\section{Availability of data and materials}

The datasets used and/or analyzed during the current study are available from the corresponding author upon reasonable request.

Ethics approval and consent to participate

Not applicable.

Consent for publication

Not applicable.

\section{Competing interests}

The authors declare that they have no competing interests.

\footnotetext{
Author details

${ }^{1}$ Department of Gastrointestinal Surgery, Affiliated Hospital of Nantong University, Nantong, China. ${ }^{2}$ Research Center of Clinical Medicine, Nantong University, Affiliated Hospital of Nantong University, Nantong, China. ${ }^{3}$ Department of Gastroenterology, Affiliated Hospital of Nantong University, Nantong, China. ${ }^{4}$ Department of Gastroenterology, The First Hospital of Jiaxing, Affiliated Hospital of Jiaxing University, Jiaxing, China. ${ }^{5}$ Blood Center of Jiangsu Province, Nanjing, China.
} 
Received: 21 September 2020 Revised: 12 December 2020 Accepted: 16 December 2020

Published online: 06 January 2021

\section{References}

1. Torre LA, Bray F, Siegel RL, Ferlay J, Lortet-Tieulent J, Jemal A. Global cancer statistics, 2012. CA Cancer J Clin. 2015;65(2):87-108.

2. Bray F, Ferlay J, Soerjomataram I, Siegel RL, Torre LA, Jemal A. Global cancer statistics 2018: GLOBOCAN estimates of incidence and mortality worldwide for 36 cancers in 185 countries. CA Cancer J Clin. 2018;68(6):394-424

3. Hanahan D, Weinberg RA. Hallmarks of cancer: the next generation. Cell. 2011;144(5):646-74.

4. Menendez JA. Fine-tuning the lipogenic/lipolytic balance to optimize the metabolic requirements of cancer cell growth: molecular mechanisms and therapeutic perspectives. Biochim Biophys Acta. 2010;1801(3):381-91.

5. Yi M, Li J, Chen S, Cai J, Ban Y, Peng Q, Zhou Y, Zeng Z, Peng S, Li X, et al. Emerging role of lipid metabolism alterations in Cancer stem cells. J Exp Clin Cancer Res. 2018;37(1):118.

6. Donohoe CL, Lysaght J, O'Sullivan J, Reynolds JV. Emerging Concepts Linking Obesity with the Hallmarks of Cancer. Trends Endocrinol Metab. 2017;28(1):46-62

7. Saito Y, Li L, Coyaud E, Luna A, Sander C, Raught B, Asara JM, Brown M, Muthuswamy SK. LLGL2 rescues nutrient stress by promoting leucine uptake in ER(+) breast cancer. Nature. 2019;569(7755):275-9.

8. Lieth E, LaNoue KF, Berkich DA, Xu B, Ratz M, Taylor C, Hutson SM. Nitrogen shuttling between neurons and glial cells during glutamate synthesis. J Neurochem. 2001;76(6):1712-23.

9. Eagle $\mathrm{H}$. Nutrition needs of mammalian cells in tissue culture. Science. 1955:122(3168):501-14

10. DeBerardinis RJ, Cheng T. Q's next: the diverse functions of glutamine in metabolism, cell biology and cancer. Oncogene. 2010:29(3):313-24.

11. Tonjes M, Barbus S, Park YJ, Wang W, Schlotter M, Lindroth AM, Pleier SV, Bai AHC, Karra D, Piro RM, et al. BCAT1 promotes cell proliferation through amino acid catabolism in gliomas carrying wild-type IDH1. Nat Med. 2013;19(7):901-8

12. Huang CS, Ge P, Zhou ZH, Tong L. An unanticipated architecture of the 750-kDa alpha6beta6 holoenzyme of 3-methylcrotonyl-CoA carboxylase. Nature. 2011:481(7380):219-23.

13. Huang CS, Sadre-Bazzaz K, Shen Y, Deng B, Zhou ZH, Tong L. Crystal structure of the alpha(6)beta(6) holoenzyme of propionyl-coenzyme A carboxylase. Nature. 2010;466(7309):1001-5.

14. Moss J, Lane MD. The biotin-dependent enzymes. Adv Enzymol Relat Areas Mol Biol. 1971;35:321-442.

15. Gallardo ME, Desviat LR, Rodriguez JM, Esparza-Gordillo J, Perez-Cerda C, Perez B, Rodriguez-Pombo P, Criado O, Sanz R, Morton DH, et al. The molecular basis of 3-methylcrotonylglycinuria, a disorder of leucine catabolism. Am J Hum Genet. 2001;68(2):334-46.

16. Baumgartner MR, Almashanu S, Suormala T, Obie C, Cole RN, Packman S, Baumgartner ER, Valle D. The molecular basis of human 3-methylcrotonylCoA carboxylase deficiency. J Clin Invest. 2001;107(4):495-504.

17. Wirth M, Karaca S, Wenzel D, Ho L, Tishkoff D, Lombard DB, Verdin E, Urlaub H, Jedrusik-Bode M, Fischle W. Mitochondrial SIRT4-type proteins in Caenorhabditis elegans and mammals interact with pyruvate carboxylase and other acetylated biotin-dependent carboxylases. Mitochondrion. 2013;13(6):705-20.

18. Anderson KA, Huynh FK, Fisher-Wellman K, Stuart JD, Peterson BS, Douros JD, Wagner GR, Thompson JW, Madsen AS, Green MF, et al. SIRT4 Is a Lysine deacylase that controls leucine metabolism and insulin secretion. Cell Metab. 2017;25(4):838-55 e815.

19. Liu Y, Yuan Z, Song C. Methylcrotonoyl-CoA carboxylase 2 overexpression predicts an unfavorable prognosis and promotes cell proliferation in breast cancer. Biomark Med. 2019;13(6):427-36.
20. Marques RB, Dits NF, Erkens-Schulze S, van ljcken WF, van Weerden WM, Jenster $\mathrm{G}$. Modulation of androgen receptor signaling in hormonal therapy-resistant prostate cancer cell lines. PLoS One. 2011;6(8):e23144.

21. Pang J, Liu WP, Liu XP, Li LY, Fang YQ, Sun QP, Liu SJ, Li MT, Su ZL, Gao $X$. Profiling protein markers associated with lymph node metastasis in prostate cancer by DIGE-based proteomics analysis. J Proteome Res. 2010;9(1):216-26

22. Dai W, Feng H, Lee D. MCCC2 overexpression predicts poorer prognosis and promotes cell proliferation in colorectal cancer. Exp Mol Pathol. 2020;115:104428

23. He J, Mao Y, Huang W, Li M, Zhang H, Qing Y, Lu S, Xiao H, Li K. Methylcrotonoyl-CoA Carboxylase 2 Promotes Proliferation, Migration and Invasion and Inhibits Apoptosis of Prostate Cancer Cells Through Regulating GLUD1-P38 MAPK Signaling Pathway. Onco Targets Ther. 2020;13:7317-27.

24. Yang R, Wu Y, Ming Y, Xu Y, Wang S, Shen J, Wang C, Chen X, Wang Y, Mao R, et al. A super-enhancer maintains homeostatic expression of Regnase-1. Gene. 2018;669:35-41.

25. Xu Y, Wu Y, Zhang S, Ma P, Jin X, Wang Z, Yao M, Zhang E, Tao B, Qin Y, et al. A Tumor-Specific Super-Enhancer Drives Immune Evasion by Guiding Synchronous Expression of PD-L1 and PD-L2. Cell Rep. 2020;32(4):108000.

26. Tang Z, Li C, Kang B, Gao G, Li C, Zhang Z. GEPIA: a web server for cancer and normal gene expression profiling and interactive analyses. Nucleic Acids Res. 2017;45(W1):W98-102.

27. Son SM, Park SJ, Lee H, Siddiqi F, Lee JE, Menzies FM, Rubinsztein DC. Leucine Signals to mTORC 1 via Its Metabolite Acetyl-Coenzyme A. Cell Metab. 2019;29(1):192-201 e197.

28. Zhang BK, Moran AM, Bailey CG, Rasko JEJ, Holst J, Wang Q. EGF-activated PI3K/Akt signalling coordinates leucine uptake by regulating LAT3 expression in prostate cancer. Cell Commun Signal. 2019;17(1):83.

29. Llovet JM, Burroughs A, Bruix J. Hepatocellular carcinoma. Lancet. 2003;362(9399):1907-17.

30. Llovet JM, Ricci S, Mazzaferro V, Hilgard P, Gane E, Blanc JF, de Oliveira AC, Santoro A, Raoul JL, Forner A, et al. Sorafenib in advanced hepatocellular carcinoma. N Engl J Med. 2008;359(4):378-90.

31. He AR, Goldenberg AS. Treating hepatocellular carcinoma progression following first-line sorafenib: therapeutic options and clinical observations. Therap Adv Gastroenterol. 2013;6(6):447-58.

32. Wang $Q$, Holst J. L-type amino acid transport and cancer: targeting the mTORC1 pathway to inhibit neoplasia. Am J Cancer Res. 2015;5(4):1281-94.

33. Reeds PJ. Dispensable and indispensable amino acids for humans. J Nutr. 2000;130(7):1835S-1840S

34. Metges CC. Contribution of microbial amino acids to amino acid homeostasis of the host. J Nutr. 2000;130(7):1857S-1864S.

35. Payne SH, Loomis WF. Retention and loss of amino acid biosynthetic pathways based on analysis of whole-genome sequences. Eukaryot Cell. 2006;5(2):272-6.

36. Sivanand S, Vander Heiden MG. Emerging roles for branched-chain amino acid metabolism in cancer. Cancer Cell. 2020;37(2):147-56.

37. Schmidt S, Gay D, Uthe FW, Denk S, Paauwe M, Matthes N, Diefenbacher ME, Bryson S, Warrander FC, Erhard F, et al. A MYC-GCN2-elF2alpha negative feedback loop limits protein synthesis to prevent MYC-dependent apoptosis in colorectal cancer. Nat Cell Biol. 2019;21(11):1413-24.

38. Romero AM, Ramos-Alonso L, Alepuz P, Puig S, Martinez-Pastor MT. Global translational repression induced by iron deficiency in yeast depends on the Gcn2/elF2alpha pathway. Sci Rep. 2020;10(1):233.

\section{Publisher's Note}

Springer Nature remains neutral with regard to jurisdictional claims in published maps and institutional affiliations. 